\title{
Em Companhia dos Livros: Graciliano Ramos E Outros Autores ${ }^{1}$
}

\author{
Sylvia Leser de Mello \\ Instituto de Psicologia - USP
}

U

m pouco à maneira de Machado de Assis, vou fazer uma advertência aos ouvintes. Como não sou especialista em letras ou crítica literária, não vou fazer uma análise literária de Graciliano e nem mesmo vou falar apenas sobre ele. Reconheço minhas limitações. Vou falar como uma leitora. Uma leitora, toda a vida apaixonada pela literatura. É um pouco sobre essa paixão que desejo falar, com a esperança de seduzi-los para a intensa vida do espírito que os livros podem proporcionar. Portanto, é sob o signo da paixão que pretendo falar sobre a literatura e o prazer da leitura. Mas não é uma paixão cega. Pelo contrário. A convivência diária com um bom livro, seja apenas um pequeno poema na hora de deitar, afia nossa capacidade de percepção que é necessariamente limitada, fechada no círculo restrito da vida de cada dia e aprisionada entre os nossos cinco sentidos. Vejam, por exemplo, um hai-kai (uma forma de poesia japonesa, concisa e precisa) do mestre Issa:

Cerejeiras do anoitecer -

Hoje também

Já é outrora.

Ou um outro de Paulo Leminski:

a noite

me pinga uma estrela no olho

e passa

1 Texto apresentado como palestra, no Instituto de Psicologia da Universidade de São Paulo, a convite do Centro Acadêmico lara lavelberg do IPUSP.

2 Docente do Departamento de Psicologia Social e do Trabalho do Instituto de Psicologia da Universidade de São Paulo. Endereço eletrônico: sldmello@usp.br 
Ou uma narrativa de Kafka:

Pequena Fábula

-Ah - disse o camundongo -, a cada dia o mundo se torna mais estreito. No início ele era tão amplo que eu tinha medo, continuei correndo e fiquei feliz por finalmente avistar, à esquerda e à direita, muros ao longe, mas esses longos muros correm tão rápido um na direção do outro que já estou no último quarto e ali, no canto, está parada a armadilha para dentro da qual vou correndo.

- você apenas precisava alterar a direção da corrida - disse o gato, e devorou-o.

Usar a literatura como um travesseiro, permitir que as palavras embalem o sono.

Mas a literatura é uma paixão que pode nos deixar espertos, sensíveis, capazes de penetrar as camadas de dissimulação da caixa preta que os psicólogos costumam chamar de subjetividade.

Não é, pois, uma paixão que incapacita. A multiplicidade de olhares sobre a vida que a literatura nos oferece poderia até mesmo ser considerada uma razão prática. Um grande escritor faz desenrolar diante da nossa inteligência, num mesmo livro, através das experiências de seus personagens, olhares tão diversos sobre a vida, que é como se estivéssemos dentro do espaço do mundo, vivendo com eles as suas circunstâncias, aventuras, dramas e tragédias. Essa razão prática por si só justificaria a aproximação da psicologia e da literatura. Experiências radicais que não têm lugar em nossas vidas, como o assassinato, por exemplo, estão ao nosso dispor nos livros: Dostoeivski, Camus, Graciliano Ramos, entre muitos outros, desafiam a nossa imaginação e nos tornam cúmplices de seus sujeitos assassinos. Vivemos a torpeza de suas motivações, a ansiedade dos momentos que precedem o crime, o medo que o secunda. Raskolnikof, Merceau, Luis da Silva nos preparam para descobrir o que movimenta a mão do matador, qual a emoção essencial que liga a vida à morte.

Para não estender demasiado este ponto de vista da razão prática, é bom lembrar ainda duas coisas: a primeira é prática mesmo, pois os livros que contam essas coisas maravilhosas podem estar sempre ao nosso alcance. É fácil folhear um livro, encontrar passagens que atraem, que inquietam ou maravilham. Olhar os livros é um raro prazer, quase como um encontro amoroso satisfatório porque completo. 
A segunda razão vou tomar de Borges e de Cortázar. Borges assimila o mundo à biblioteca num conto denominado A Biblioteca de Babel, onde tudo estaria escrito, em todas as línguas: ela é o mundo, e a sua exploração, que tomaria toda a vida, é impossível. Mas ler o conto é indispensável. Ele não pode ser reduzido.

As palavras de Cortázar (1993), são, de algum modo, uma paródia simplificada de Borges. Ele diz:

tenho pensado algumas vezes se a literatura não merecia ser considerada uma empresa de conquista verbal da realidade... [a cada momento] descobre-se que cada livro realiza a redução ao verbal de um pequeno fragmento da realidade, e que a acumulação de volumes em nossa biblioteca vai parecendo cada vez mais com um microfilme do universo; materialmente pequeno, mas com uma projeção em cada leito que devolve as coisas ao seu tamanho mental primitivo.... a literatura vai apoderando-se das coisas... e de certa forma as subtrai, rouba-as ao mundo. (pp.61-62)

E chegamos a Graciliano Ramos, escritor e leitor. Um homem singular, como todos nós. Mas um artista, o que não acontece a todos. A relação privilegiada com a leitura nos é descrita já em seus primeiros anos de vida, quando era capaz de enfrentar a ira paterna e materna para ler histórias, isolar-se para percorrer outros mundos que os colegas da escola nem chegavam a suspeitar. Em seu livro de memórias - Infância - ele relata como a leitura ofereceu, ao menino pobre e humilhado das Alagoas, matéria que deu sentido ao mundo externo e substância ao seu mundo interior:

Nesse tempo eu andava nos fuzuês de Rocambole. Jerônimo Barreto me fazia percorrer diversos caminhos: revelara-me Joaquim Manuel de Macedo, Júlio Verne, afinal Ponson du Terrail, em folhetos devorados na escola, debaixo das laranjeiras do quintal, nas pedras do Paraíba, em cima do caixão de velas, junto ao dicionário que tinha bandeiras e figuras.

Os meus colegas se afastavam de mim, declamavam as capitais, os rios da Europa. E eu mascava os prolegômenos: vinte e quatro horas, trezentos e sessenta e cinco dias, raça branca, raça negra. Quando tomei pé na Europa, eles exploravam outras partes do mundo. Surdo às explicações dos mestres, alheio aos remoques dos garotos, embrenhava-me na leitura do precioso fascículo, escondido entre as folhas de um atlas. Às vezes procurava na carta os lugares que o ladrão terrível percorrera. E o mapa crescia, povoava-se, riscava-se de estradas por onde rodavam caleças e diligências. 
Conheci desse jeito várias cidades, vivi nelas, enquanto os pequenos em redor se esgoelavam, num barulho de feira. O rumor não me atingia. Em vão me falavam. Sacudido, sobressaltava-me, as idéias ausentes, como se me arrancassem do sono. Olhavam-me estupefatos, devagar me inteirava da realidade....

Eu achava estupidez pretenderem obrigar-me a papaguear de oitiva. Desonestidade falar de semelhante maneira, fingindo sabedoria. Ainda que tivesse de cor um texto incompreensível, calava-me diante do professor - e a minha reputação era lastimosa.

Um dia, porém, houve exame imprevisto e os alunos encrencaram nos rios e nas capitais. Haviam-me chegado pedaços disso. Geografia velha, anterior à locomotiva, cheia de soluções de continuidade, mas foi exposta e produziu efeito regular. Mencionei o bosque de Bolonha, Versalhes, o Sena, a torre de Londres, as pontes de Veneza, o Reno e o Tibre, o porto de Marselha. Não era exatamente o que desejavam. Em todo caso fui ouvido. Certas interrupções me avivavam a eloquência. $\mathrm{O}$ Mediterrâneo? Perfeitamente, a Córsega, terra de Napoleão. Da poeira de Ajácio ao trono de S. Luís. Jerônimo Barreto me falara na poeira e no trono - e isto não apresentava dificuldade: Ajácio estava ali no mapa, S. Luís tinha sido rei da França, Napoleão se estrepara na campanha da Rússia, logo nas primeiras páginas do Rocambole. Num desconchavo, referi-me à catedral de Notre-Dame e ao Vesúvio familiarmente, como se os tivesse visto. Além disso arrolei plantas e animais exóticos: carvalhos e pinheiros, vinhedos e trigais, lobos e javalis, melros e rouxinóis. (1961, pp. 232-234)

Ler Infância, de Graciliano Ramos, é apropriar-se de uma chave para a leitura de seus livros. Como diz Antonio Candido (1992), embora a crítica afirme

que a obra vale por si, e em si mesma deve ser considerada, independente da pessoa do escritor, nunca nos furtamos à curiosidade que este desperta. Se cada livro pode dar lugar a um interesse apenas imediato, isto é, esgotado pelo que ele pode oferecer, uma obra, em conjunto, nos leva quase sempre a averiguar a realidade que nela se exprime e as características do homem a quem devemos esse sistema de emoções e fatos tecidos pela imaginação. (p. 49)

Nas palavras do mestre Antonio Candido encontramos uma linha condutora para o que é uma inquietação permanente. Graciliano talvez seja, e eu acrescentaria Proust e Kafka, um artista peculiar quanto às relações que se podem estabelecer entre ficção e confissão, entre ficção e realidade, entre a vida e a leitura que se pode fazer dela.

Em Infância o sentimento mais presente é o da humilhação de menino sensível, permanentemente machucado pelos pais. "Por toda parte, recorda- 
ções doídas de alguma injustiça, de alguma vitória descarada do forte sobre o fraco" (Ramos, 1992, p. 50). Mais uma vez se pode aproximar, sem susto, Graciliano e Kafka. A violência do adulto, que aos olhos infantis é sempre mais forte, e não só fisicamente, marca profundamente a criança. Kafka acusa o pai de havê-lo incapacitado para a vida normal de um adulto, que ele compreendia como sendo a via do casamento, dos filhos, da burguesia. Graciliano não acusa. Descreve e fábula, pois é um romancista. Mas em suas obras de ficção mesmo os personagens fortes, como Paulo Honório, de São Bernardo, estão presos a uma inadequação para a vida que é, de início e sempre, consigo próprio, uma raiva de tudo, do mundo, das pessoas. Não acredita na justiça, em Deus e outros conceitos abstratos, como o amor. Assim fala Antonio Candido (1992) sobre São Bernardo:

Dois movimentos o integram: um, a violência do protagonista contra homens e coisas; outro, a violência contra ele próprio. Da primeira resulta São Bernado-fazenda, que se incorpora ao seu próprio ser, como atributo penosamente elaborado; da segunda, resulta São Bernardo-livro-de-recordações, que assinala a desintegração de sua pujança. De ambos nasce a derrota, o traçado da incapacidade afetiva. (p. 29)

Os protagonistas de Kafka sofrem a violência e encontram a morte sem saber por quê, mas é a mesma incapacidade afetiva que os move. Assim como Madalena era apenas uma aquisição necessária para a glória de São Bernardo, durante todo $O$ Processo o personagem $\mathrm{K}$ aproxima-se das mulheres para obter alguma coisa.

Manipular os acontecimentos, usar as pessoas para finalidades pessoais - aparentemente o mundo é movido assim. Não há grandes sutilezas em Paulo Honório. Ele não se detém a examinar-se, não quer dar conta de seus pensamentos senão quando acrescentam algo à narrativa de sua história. É um homem de atos. Por eles julga, por eles quer ser julgado.

O protagonista de Angústia, por sua vez, é um "frustrado violento, cruel, irremediável, que traz em si reservas inesgotáveis de amargura e negação" (Candido, 1992, p. 34). Aos atos vergonhosos Luís da Silva acrescenta um exame permanente de si. Há nojo, desespero, e "a inércia amarela e invicta" (Candido, 1992, p. 36). 
Assim como São Bernardo, Angústia é narrado em primeira pessoa. Apenas em Vidas Secas, uma obra-prima de concisão e sensibilidade, há um narrador. Usando o privilégio de não ser especialista ou crítica literária, declaro um grande encanto por Vidas Secas.

Que saborosa essa narrativa! Ainda mais quando o autor nos conta as dificuldades que precederam o prazer que a sua leitura nos dá, porque o menino Graciliano, sem graça e tímido, como se representa a si mesmo, parece pertencer a uma estirpe, hoje talvez em extinção, de leitores incansáveis, sem os quais a palavra escrita, fonte dos sonhos e da fantasia, subsistiria apenas em suas funções pragmáticas de comunicação diária e burocrática.

Falar do prazer do texto é coisa para especialista, como Barthes. Mas, como professora, posso sempre renovar o convite a vocês. No fundo, no fundo, ainda é o mesmo prazer que tinha quando, menina sem trato com o alfabeto, me contavam histórias de fadas e histórias de gentes.

\section{Referências}

Candido, A. (1992). Ficção e confissão. Ensaios sobre Graciliano Ramos. Rio de Janeiro: Editora 34.

Cortázar, J. (1993). Valise de cronópio (2a ed). São Paulo: Perspectiva.

Ramos, G. (1961). Infância. São Paulo: Martins.

Recebido em: 6/12/2006

Aceito em: 11/12/2006 